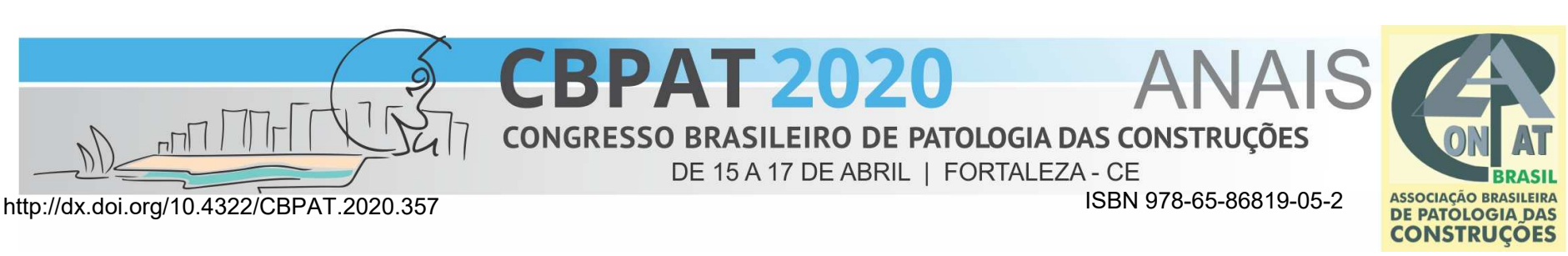

\title{
CONSOLIDAÇÃO ESTRUTURAL DO PATRIMÓNIO ARQUITETÓNICO
}

\author{
FRANCO, CARLOS MANUEL \\ Arquiteto Mestre, doutorando \\ Universidade Lusófona de Lisboa \\ Lisboa, Portugal \\ cmfrancopt@gmail.com
}

\begin{abstract}
RESUMO
O estado de abandono em que se encontra o património arquitetónico, grande parte em estado avançado de degradação, seja público ou de propriedade privada, compromete não só a preservação de um legado que nos foi confiado, como também põe em perigo a própria segurança de todos na sua envolvente próxima, pelo que se impõe uma prévia e adequada estabilização estrutural do edifício, estabelecendo as condições de firmeza para a sua reabilitação integral. A compreensão da tectónica original do edifício e o reconhecimento das suas características históricas e morfológicas, será fundamental para uma consciente tomada de decisão de atuação - numa intervenção que se deseja mínima e pouco intrusiva, facilitando a otimização de soluções em função do estado de conservação em que o edifício se encontre. A metodologia que se apresenta de registo e interpretação do Património Arquitetónico, aplicada ao estudo do sistema estrutural, permitirá de uma forma mais segura definir critérios de intervenção mais assertivos face a cada objeto alvo de estudo. Minimizar as intervenções de reabilitação surge como uma consequência de um princípio muito mais geral e abrangente: o da Sustentabilidade. Reduzir a intervenção ao mínimo, preservando os valores que asseguram a sua identidade e autenticidade, tendo em consideração os critérios de ordem económica, social e ambiental, será o grande desafio.
\end{abstract}

Palavras-chave: patologias da construção, estabilização estrutural, reabilitação.

\begin{abstract}
The state of abandonment in which the architectural heritage is found, much of an advanced state of degradation, whether public or privately owned, compromises not only the preservation of a legacy entrusted to us, but also endangers our own security of all in its near surroundings, so a prior and adequate structural stabilization of the building is required, establishing the conditions of firmness for its integral rehabilitation. The understanding of the original tectonics of the building and the recognition of its historical and morphological characteristics, will be fundamental for a conscious decision-making of action - in an intervention that is desired minimal and intrusive, facilitating the optimization of solutions depending on the state of conservation in which the building is. The methodology that is presented with the registration and interpretation of architectural heritage, applied to the study of the structural system, will allow in a safer way to define more assertive intervention criteria against each object targeted for study. Minimizing rehabilitation interventions emerges as a consequence of a much more general and comprehensive principle: that of Sustainability. Reducing intervention to a minimum, preserving the values that ensure their identity and authenticity, taking into account economic, social and environmental criteria, will be the major challenge.
\end{abstract}

Keywords: construction pathologies, structural stabilization, rehabilitation 


\section{INTRODUÇÃO}

Proteger e potenciar o Património Arquitetónico, com recurso a intervenções de reabilitação e preservação qualificadas e sustentáveis, será o contributo que este trabalho pretende alcançar. Uma intervenção atempada e pouco intrusiva é o maior garante na preservação patrimonial, na salvaguarda da sua identidade. A sua redução ao estritamente necessário resultará em menores custos de reabilitação. Os resíduos produzidos, os materiais a utilizar e a energia necessária em todo o processo serão sempre menores numa intervenção minimizada, respeitando não só o Património com também o Ambiente, convergindo indo deste modo com os objetivos da economia circular e consequentemente com os princípios preconizados da sustentabilidade.

Infelizmente verifica-se em alguns casos em que a intervenção foi protelada e negligenciada em situações de inequívoca degradação, quer tenham sido provocada por fenómenos naturais (erosão de revestimentos e de juntas, queda de elementos estruturais) ou por incisões antrópicas, causando danos irremediáveis ao património, contribuindo significativamente para o acelerando do processo de ruina de parte ou mesmo de todo o edifício.

Com o Estudo de Caso em tempos realizado sobre um edifício em completo estado de abandono, pela relevância da sua tipologia e pelo seu inequívoco valor arquitetónico, com vista à transmissão do conhecimento científico e tecnológico e consequente endogeneização então adquirido, foi compilada toda a informação recolhida à data e pouco antes da intervenção entretanto realizada, tendo-se ainda incluindo registos fotográficos já na fase inicial de obra.

O objetivo deste artigo é estabelecer uma metodologia de intervenção, numa abordagem direcionada à avaliação do sistema estrutural, definindo como prioridade a estabilização global do edifício. A avaliação prévia do estado de conservação do edifício, através da observação in loco das patologias e anomalias provocadas por anos de abandono, vem possibilitar a definição de um conceito apropriado para uma estabilização estrutural, que possa vir a ser replicado em edifícios semelhantes, não só em Portugal como também em qualquer parte do mundo em que existam exemplares de reconhecido interesse arquitetónico, privilegiando a adoção de soluções pouco intrusivas, apostando na recuperação e a reabilitação dos materiais e das técnicas construtivas tradicionais que fazem parte do conjunto de valores culturais materializados no edifício, onde a adaptação às novas exigências regulamentares de uso e de desempenho estrutural, constitui um desafio adicional ao qual se pretende dar uma resposta, de forma a satisfazer os requisitos de conforto, eficácia funcional e de sustentabilidade. A investigação foi complementada com pesquisas em obras e suportada em trabalhos científicos publicados sobre a problemática da reabilitação e - agora mais que nunca, também sob uma perspetiva de sustentabilidade tão pertinente, com relevância obvia para o futuro do arquiteto e da arquitetura. Contribuir para a mudança de atitude de passividade geral sobre um legado que nos foi confiado, que urge ser cuidado num cumprimento da obrigação de termos de transmiti-lo às gerações vindouras.

Previamente às intervenções em Património Arquitetónico classificado (tombado) e em fase de projeto, deverá se considerar não só a legislação aplicável de âmbito nacional, como também as cartas e recomendações, critérios e normas internacionais sobre proteção de Património Arquitetónico. A legislação portuguesa estabelece as bases da política e do regime de proteção e valorização do património cultural - Lei no ${ }^{\circ} .107 / 2001$ de 8 de Setembro, conjugado com o Decreto-

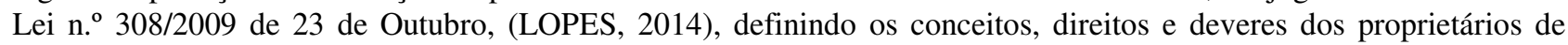
património com interesse cultural relevante, designadamente arquitetónico, com valores de memória, antiguidade, autenticidade, originalidade, raridade, singularidade ou exemplaridade, sendo tarefa fundamental do Estado e dever dos cidadãos, a sua proteção e a valorização. Os estudos e projetos para as obras de conservação, modificação, reintegração e restauro em bens classificados (tombados), ou em vias de classificação (tombamento), terão de ser elaborados e subscritos por técnicos de qualificação legalmente reconhecida ou sob a sua responsabilidade direta, sendo que as obras ou intervenções, serão objeto de autorização e acompanhamento do órgão competente para a decisão final do procedimento de classificação (tombamento). O Estado, os municípios e os proprietários ou titulares de outros direitos reais de gozo sobre imóveis classificados (tombados) devem executar todas as obras que a administração do património cultural competente considere necessárias para assegurar a sua salvaguarda, podendo as entidades públicas competentes promover a sua execução coerciva, no caso de as obras ou intervenções não terem sido iniciadas ou concluídas dentro do prazo fixado (Lei $n^{\circ} .107 / 2001$ de 8 de Setembro).

No Brasil, e independentemente de se tratar de uma pequena intervenção como seja a simples pintura de fachadas, ou uma intervenção que contemple uma ampliação da construção, será necessário uma autorização prévia emitida pelo órgão responsável pelo tombamento (classificação). Para obras maiores torna-se obrigatória a elaborar um projeto arquitetónico 
descrevendo o tipo de intervenção, subscrito por um arquiteto, de acordo com a Lei Federal 12.378/2010. Não obstante ser da responsabilidade do proprietário a promoção de todas as obras necessárias à preservação do bem, a lei brasileira prevê que em caso de o proprietário ou titular de posse não possuir recursos suficientes para promover as necessárias obras, caberá ao órgão responsável pelo tombamento (classificação), realizar as intervenções que se considerarem necessárias para assegurar a sua preservação (PAIVA \& SOUZA, 2018).

\section{ESTUDO DE CASO}

Para Raquel Henriques da Silva, 2011 in Arquitectura de veraneio: alguns tópicos sobre o que é e algumas pistas param o que falta saber (SOUSA, 2011) “As casas que são capazes de propor este encontro determinante são, sem qualquer dúvida, grande arquitetura. E, como todos os modelos bem-sucedidos, possuem ampla e mesclada descendência onde a arte cruza permanentemente com a (s) vida (s), o que é outra nobre função da arquitetura"

O caso de estudo apresentado avalia um importante exemplo oitocentista de edificação habitacional privada [Figura 1], em pleno centro histórico da Vila de Cascais, Portugal, conjugando em simultâneo duas tendências - romântica e neoclássica, duas correntes estilísticas mais relevantes a nível internacional do século XIX. Como principais características deste tipo de arquitetura, destacam - se as suas linhas ortogonais, as formas regulares, geométricas e simétricas bem como o pórtico colunado. Constituída por uma planta quase quadrangular $(10,24 \times 11,73 \mathrm{~m})$, de três pisos sobrepostos, com uma área aproximada de $132,00 \mathrm{~m}^{2}$ por piso, evidenciados exteriormente nas fachadas através de cornijas que formam arquitraves.

A sua verticalidade é assumida pela elevação de 2,60m do piso nobre em relação ao logradouro, impondo-se desta forma sobre a praça pública. A comunicação vertical entre os diferentes pisos é assegurada pela escada estrategicamente colocada sob o eixo transversal do edifício, em que os vãos existentes na fachada nascente asseguram a iluminação e ventilação natural do espaço interior. O pórtico de colunas de fuste quadrado, assentes sobre uma base também ela quadrada, suportando a varanda de balaustrada em cantaria, assinala imponentemente a entrada principal da Casa [Figura 1]. Branca Colaço e Maria Archer enfatizavam a sua beleza e elegância, numa analogia com a Capital cosmopolita: “(...) essa airosa moradia que tem um pórtico de colunata no género do que o Teatro Nacional vira para o Rossio (...) " (COLAÇO \& ARCHER, 2013)

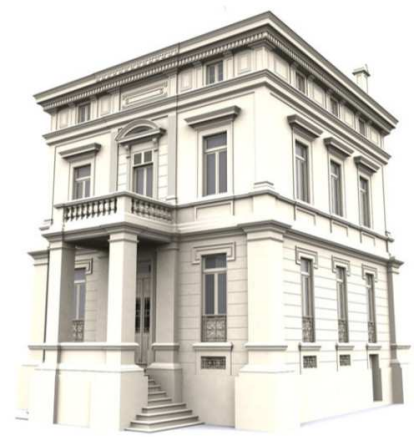

Figura 1: Casa Sommer - modelo 3D. Fonte: Geostar, Levantamentos arquitectónicos).

\subsection{Caracterização estrutural}

\subsubsection{Paredes exteriores e interiores}

O edifício foi construído a partir de uma base quase quadrangular $(10,24 \times 11,73 \mathrm{~m})$, geometria essa que lhe confere favorável uma boa prestação sob o ponto de vista de comportamento sísmico. As paredes exteriores foram construídas em alvenaria irregular de pedra de dois panos, de talhe aparelhado em ambas as faces e com orientação horizontal apainelada, do tipo de alvenaria com juntas de argamassa, preenchimento do núcleo interior com pedras de menores dimensões (MASCARENHAS, 2019). Nesta tipologia construtiva as pedras são assentes umas sobre as outras - em mata junta, envolvidas em argamassa de cal e areia - habitualmente na época ao traço de 1:2 (1 parte de cal e 2 partes de areia), na qual se introduzem transversalmente cacos cerâmicos e escacilhos de pedra de forma a preencher os espaços vazios, conferindo não só melhor aderência dos elementos como permitindo também a execução de leitos regulares para 
assentamento das sucessivas camadas. As paredes são suportadas por fundações diretas, num simples prolongamento das mesmas com alargamento já no solo, de idêntica composição construtiva. A espessura da parede é variável:0,75m desde as fundações até à cota do patamar da escadaria do frontal; 0,65 m deste nível até à soleira do Piso 2; 0,60 na envolvência exterior dos Pisos 2 e 3. O arranque dos cunhais em forma de pilastras, visa aumentar a sua área de contato com o terreno e consequentemente uma melhoria na distribuição de cargas, assume uma saliência resultante da diferença da sua geometria de embasamento de 1,00x1,00m, das fundações até à cota do patamar da escadaria do frontal, a partir daqui reduz-se no para $0,80 x 0,80 \mathrm{~m}$. Nos rebocos era comum a aplicação de argamassa de cal ao traço1:3 (1 parte de cal e 3 partes de areia grossa e fina em igual quantidade). Os rebocos eram executados em sucessivas camadas, conseguindo-se deste modo minimizar os efeitos cíclicos das contrações/dilatações a que estão sujeitos os diferentes materiais, aumentando consideravelmente a durabilidade da obra no seu todo. As paredes interiores do Piso Térreo [Figura 2], são também em alvenaria irregular de pedra, em tudo idêntica à tipologia das paredes exterior, com exceção da espessura que é de $0,40 \mathrm{~m}$ de espessura, formando o arranque da caixa de escada e o suporte das paredes do corredor axial da casa, conferem a rigidez necessária ao embasamento geral do edifício.

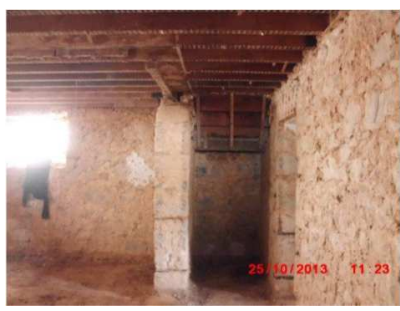

Figura 2: Paredes estruturais. Fonte: do autor.

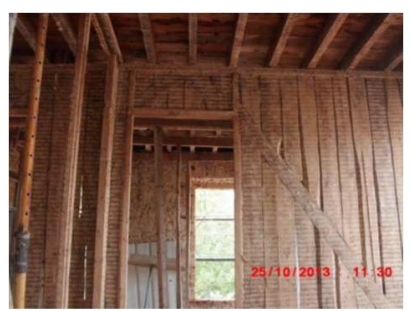

Figura 3: Estrutura parede de tabique. Fonte: do autor.

As paredes interiores em tabique de madeira dos restantes pisos [Figura 3] têm não só como utilidade de compartimentação dos espaços como também a função de travamento estrutural do edifício “ nos edifícios antigos desempenham quase sempre uma função estrutural de relevo, já que a própria arquitetura dos edifícios, a organização dos espaços e as limitações estruturais dos elementos disponíveis fazem com que se mobilize a capacidade resistente da generalidade das paredes. "(APPLETON, 2011). Os tabiques constituídos por uma estrutura de costaneiras de madeira de casquinha, num conjunto de peças verticais, horizontais e diagonais - cruzes de $\mathrm{St}^{\circ}$. André, entalhadas e pregadas de forma a permitir o seu encaixe simultaneamente entre si e aos frechais, estabelecendo a ligação aos pavimentos. $O$ fasquiado horizontal de secção trapezoidal, igualmente em casaquinha, serve de suporte ao reboco de argamassa fraca de areia e cal aérea cujo traço usual na época era de 1:3, - 1 parte de cal e 3 partes de areia, de fraca retração e fraca resistência mecânica, conferindo boa aderência à base e boa trabalhabilidade (APPLETON, 2011).

\subsubsection{Pavimentos}

A estrutura dos pavimentos dos pisos elevados é composta por elementos em madeira de casquinha branca, aplicado sob a forma de soalho à portuguesa, com espessura de $0,03 \mathrm{~m}$ e de largura variável $(0,12 / 0,15 \mathrm{~m})$, assentes sobre vigas com $0,17 \times 0,08 \mathrm{~m}$ dispostas na direção do menor vão, encastradas nas paredes exteriores, com um afastamento entre si de $0,36 \mathrm{~m}$ [Figura 4].

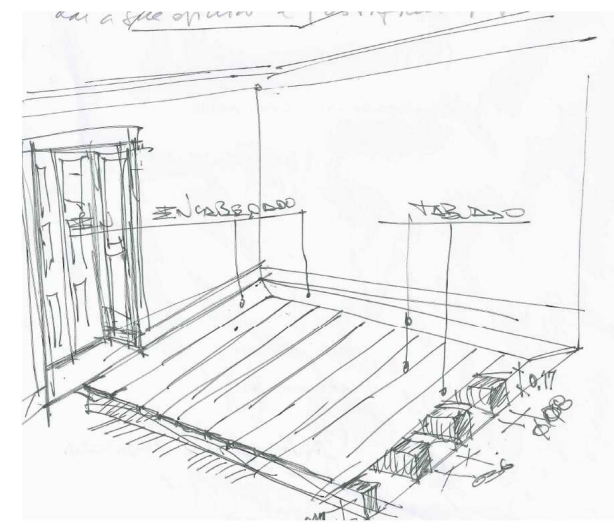

Figura 4: Levantamento in situ da estrutura de pavimento. Fonte: Elaborado pelo autor 


\subsubsection{Coberturas}

A cobertura é em madeira de casquinha branca, com quatro águas simétricas, de estrutura constituída por duas asnas, fixadas ao frechal existente no seu perímetro, interligadas por barrotes e ripas de suporte ao revestimento em telha cerâmicas [Figura 5].

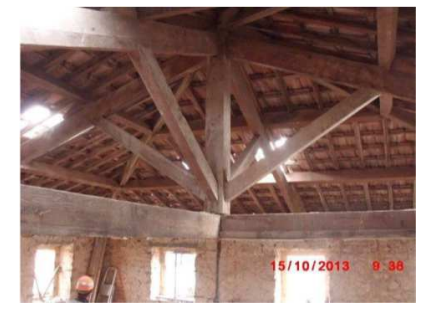

Figura 5: Estrutura da cobertura. Fonte: do autor

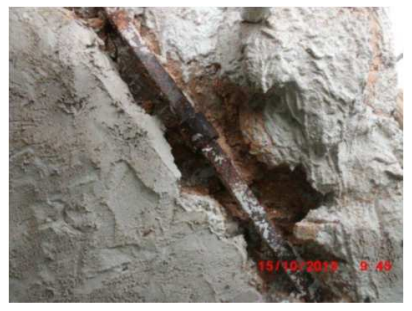

Figura 6: Ferrolho metálico. Fonte: do autor

A tipologia estrutural da cobertura, em conjunto com dispositivos de ligação às paredes exteriores, com recurso à aplicação de peças metálicas designadas por ferrolhos [Figura 6] (COIAS, 2007), ancorados no lado exterior da parede, na direção transversal das vigas, garante no seu conjunto o necessário contraventamento do edifício.

\subsection{Determinação do índice de anomalias}

Para determinação do nível de conservação, em visita ao edifício em análise, com base na inspeção das anomalias visíveis segundo os critérios e as regras de avaliação constantes da Ficha de Avaliação desenvolvida pelo Laboratório Nacional de Engenharia Civil (LNEC), no quadro disponibilizado no endereço eletrónico do Portal da Habitação. O LNEC concebeu assim o Método de Avaliação do Estado da Conservação de edifícios (MAEC) que visa determinar com rigor, objetividade e transparência o estado de conservação de edifícios e a existência de Infraestruturas básicas. A ficha de avaliação, aprovada pela Portaria n. ${ }^{\circ} 1192-\mathrm{B} / 2006$ de 3 de Novembro, publicada no Diário da República, 1.a série- n. ${ }^{\circ}$ 212-3 de Novembro de 2006, agrega os elementos relevantes para a determinação do nível de conservação, nos termos do n. ${ }^{\circ} 2$ do artigo $33^{\circ}$ da Lei n..$^{\circ}$ 6/2006, de 27 de Fevereiro, que aprovou o Novo Regime do Arrendamento Urbano (NRAU).

São ainda regulados nessa portaria os critérios de avaliação e as regras necessárias à determinação do nível de conservação, ao abrigo do disposto no n. ${ }^{\circ} 2$ do artigo 1.0 do Decreto-Lei n. ${ }^{\circ} 156 / 2006$, de 8 de Agosto, e do coeficiente de conservação previsto na alínea c) do n..$^{\circ} 1$ do artigo $49^{\circ}$ do NRAU e no artigo $15^{\circ}$ do Decreto-Lei n. ${ }^{\circ} 161 / 2006$, de 8 de Agosto. A portaria estabelece no número 1 do Artigo $3^{\circ}$ os Critérios gerais de avaliação: A avaliação do nível de anomalia que afeta cada elemento funcional é realizada através da conjugação dos quatro critérios seguintes:

a) Consequência da anomalia na satisfação das exigências funcionais;

b) Tipo e extensão do trabalho necessário para a correção da anomalia;

c) Relevância dos locais afetados pela anomalia;

d) Existência de alternativa para o espaço ou equipamento afetado.

O Artigo $6^{\circ}$ define a Fórmula de cálculo em que o quociente entre o total das pontuações e o total das ponderações atribuídas aos elementos funcionais aplicáveis resulta no índice de anomalias, sendo o valor obtido aproximado com duas casas decimais, classificado segundo a escala constante da seguinte Tabela 1.

Tabela 1: Escala de intervalos para classificar o índice de anomalias (IA).

\begin{tabular}{|l|c|c|c|c|c|}
\hline \multicolumn{1}{|c|}{ Nível de anomalia } & Muito Ligeiras & Ligeiras & Médias & Graves & Muito Graves \\
\hline Índice de anomalias & $5,00 \geq \mathrm{IA} \geq 4,50$ & $4,50 \geq \mathrm{IA} \geq 3,50$ & $3,50 \geq \mathrm{IA} \geq 2,50$ & $2,50 \geq \mathrm{IA} \geq 1,50$ & $1,50 \geq \mathrm{IA} \geq 1,00$ \\
\hline Estado de conservação & Excelente & Bom & Médio & Mau & Péssimo \\
\hline Nível de conservação & 5 & 4 & 3 & 2 & 1 \\
\hline
\end{tabular}

Com base no levantamento procedeu-se ao preenchimento da Ficha de Avaliação [Figura 7] recorrendo ao simulador disponibilizado para o efeito no endereço eletrónico: 
https://www.portaldahabitacao.pt/pt/nrau/home/simuladorFichaAval.jsp, acedido em 14-01-2020, tendo-se obtido o índice de anomalias de 2,51, que consequentemente corresponde um estado de conservação considerado de Mau.

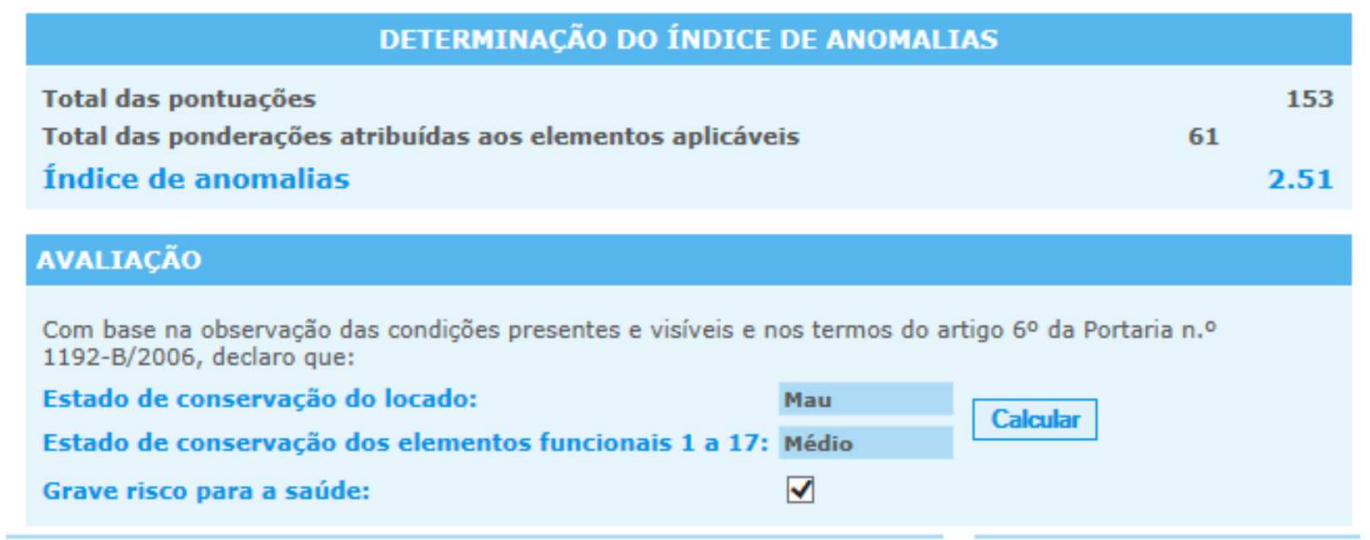

Figura 7: Simulador da Ficha de Avaliação.

Na presença de património tombado, deverá se optar por uma estratégia com base numa "abordagem observacional”, ficando, contudo, ficar garantida uma verificação assídua durante o decorrer da intervenção, da eficácia das medidas corretivas a serem propostas de forma a garantir os necessários ajustamentos face à realidade que se vier a encontrar em obra (APPLETON, 2011). As principais anomalias verificadas no levantamento realizado ao edifício, com especial preocupação no estado estrutural da construção, devendo ser assinaladas sobre as peças desenhadas previamente preparadas para o efeito - plantas, corte e alçados, que vierem a ser consideradas alvo indiscutível de correção e/ou reparação. A avaliação de aberturas de fissuras baseou-se nas sebentas de aulas dadas pelo saudoso Professor Doutor Arquiteto António Santa Rita, por se considerar um método simples e objetivo, adequado portanto a este tipo de análise. As fissuras em paredes de alvenaria são classificadas segundo os critérios relacionados, com a dimensão da abertura, a atividade, a forma, as causas, a direção.

Classificação das fissuras de acordo com a abertura:

Finas: Fissuras com abertura inferior a $1,5 \mathrm{~mm}$;

Médias: Fissuras com abertura entre $1,5 \mathrm{~mm}$ e $10,0 \mathrm{~mm}$;

Largas: Fissuras com abertura superior a $10,0 \mathrm{~mm}$

Existem ainda as Fissuras capilares - com aberturas inferiores à $0,1 \mathrm{~mm}$ - capilares, não serão referenciadas neste estudo, uma vez que se considera que as mesmas não provocam danos ao edifício.

Classificação de fissuras segunda a atividade

Fissuras ativas: com variações de abertura num determinado período de tempo. A origem dessa atividade está geralmente associada ou às variações térmicas, apresentando um comportamento cíclico alternando a sua abertura de acordo com as variações de temperatura ou pelo assentamento de fundações, apresentando normalmente uma abertura progressiva. São consideradas as mais preocupantes neste processo de monitorização, pelo que, com o decorrer dos trabalhos se deve prestar especial atenção quanto ao seu comportamento.

Fissuras estáveis: as que não apresentam variações de abertura ao longo do tempo. As suas causas poderão ser de ordem vária, designadamente provocadas por solicitações externas constantes, sobrecargas ou assentamento de fundações entretanto estabilizadas.

Classificação de fissuras segunda a sua forma:

Fissuras disseminadas: apresentam-se em forma de teia sobretudo em revestimentos, não tendo por isso origem na deformação estrutural do edifício.

Fissuras isoladas: de origens diversas de carácter estrutural ou não estrutural. Caracterizam-se por seguirem uma direção predominante, acompanhando as juntas de argamassa ou partindo componentes, seguindo fiadas horizontais ou verticais, ou, ainda, prolongando-se pela interface entre componentes da alvenaria e a junta de argamassa. 


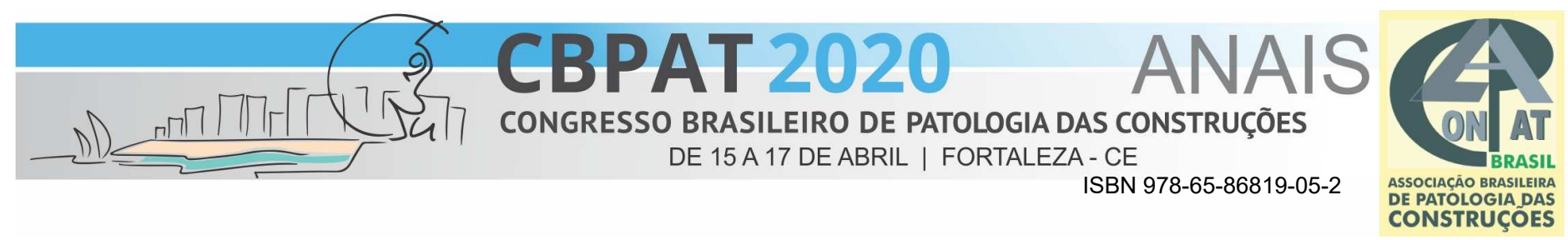

Classificação das fissuras segundo as causas:

Excessivo carregamento de compressão (sobrecargas);

Variações de temperatura;

Retração e expansão dos materiais;

Deformação dos elementos estruturais;

Assentamentos de fundações;

Reações químicas dos materiais;

Processos construtivos errados.

Classificação de fissuras segundo a direção:

A classificação da direção das fissuras pela sua simplicidade é um elemento adequado para a análise prévia das fissuras, devendo fazer parte do processo de diagnóstico. São classificadas do seguinte modo:

- Verticais

- Horizontais

- Diagonais.

A classificação de fissuras segundo as respetivas causas é talvez a mais adequada para o estudo das fissuras, pois será a partir desta análise que se definirão as soluções para o problema. Com base no descrito nas classificações de fissuras, foi elaborada a base para a catalogação das configurações típicas de fissuras em alvenarias, registando-se devidamente a sua localização nos alçados do edifício.

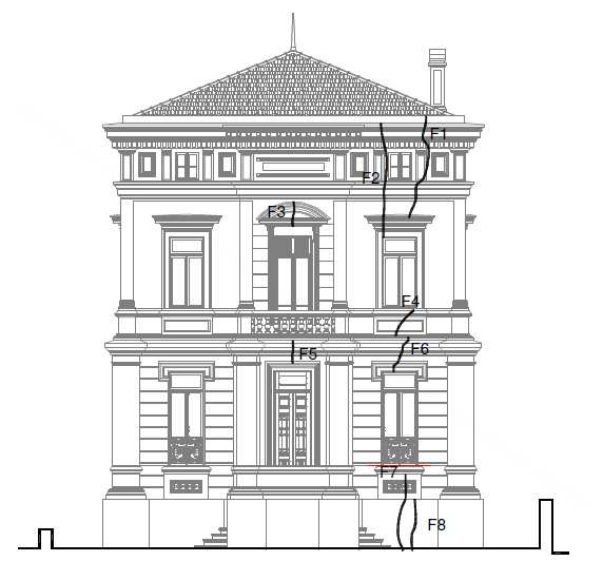

Figura 8: Fachada sul com localização de fissuras. Fonte: Elaborada pelo autor.

Paramento sul: fendas de aberturas consideráveis, provocadas pelo assentamento da fundação do cunhal sudeste, em resultado de um maior esforço de tração no sentido oeste/este, devendo merecer atenção especial na proposta de intervenção. As fissuras F1, F2, F3, F4, F5, F6, F7 e F8 [Figuras 8; 9 e 10] são assim consideradas como fissuras largas, cuja atividade necessita de ser monitorizada, com orientação diagonal de causas relacionadas com o assentamento de fundações.

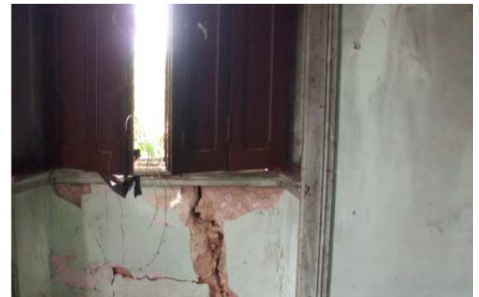

Figura 9: Fissura F4. Fonte: do autor.

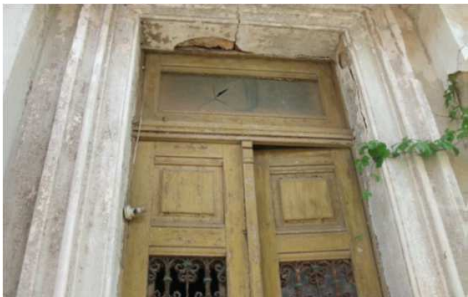

Figura 10: Fissura F5. Fonte: do autor 


\subsection{Levantamento de patologias}

Para sistematizar a informação recolhida in situ, foi elaborada uma Lista de Patologias, com base nos estudos de Patologias dos edifícios realizados pelo Laboratório de Física das Construções (LFC) da Faculdade de Engenharia da Universidade do Porto (FEUP) em colaboração com o Grupo de Estudos da Patologia da Construção - PATORREB. Agrupadas num conjunto de Fichas de Patologias, onde se descrevem não só os problemas encontrados detetados, como também se indicam as suas principais causas, os métodos de avaliação e as soluções possíveis de intervenção. Na base do preenchimento destas fichas foram considerados os levantamentos feitos no local e devidamente registados nas plantas dos pisos [Figura 11] e nos alçados [Figura 13], e que se apresentam de acordo com a simbologia constante na Figura 12 - Simbologia de representação de Patologias.

Para uma melhor interpretação e um adequado diagnóstico será necessário consultar os registos, elaborados no decorrer da inspeção prévia realizada ao edifício, expressos sobre os alçados e plantas, das patologias encontradas não só na sua envolvente exterior como também no seu espaço interior. Paralelamente à inspeção efetuada, o registo fotográfico complementar [Figuras 14; 15 e 16] torna-se imprescindível para uma leitura esclarecedora da situação encontrada durante a avaliação. Deverá então se apresentar um levantamento fotográfico completo de cada fachada, incidindo nas principais anomalias existentes.

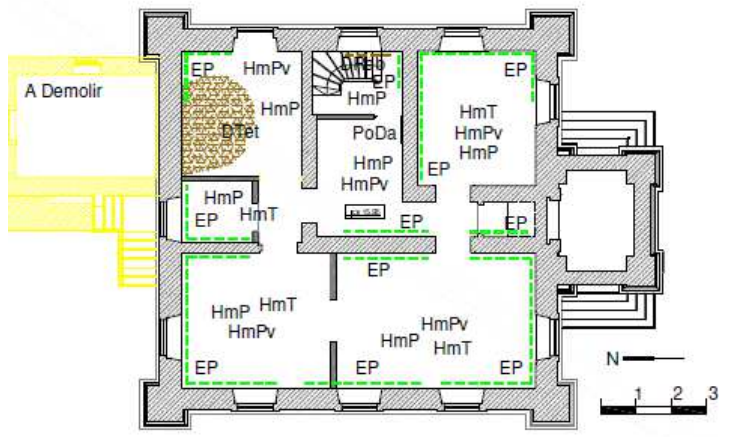

Figura 11: Registo de patologias. Fonte: do autor

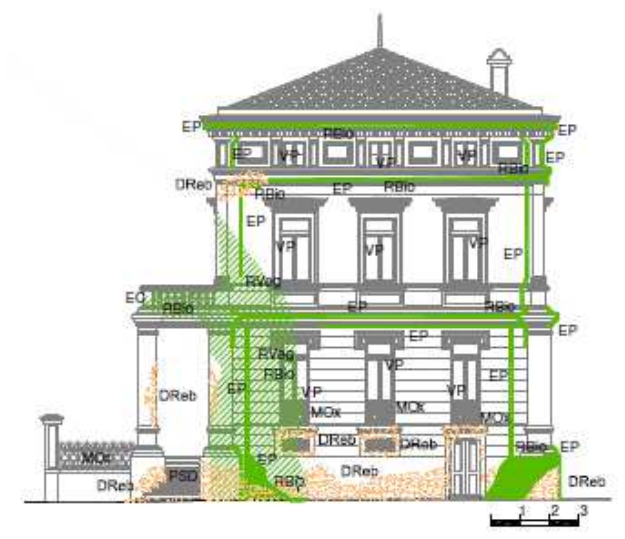

Figura 13: Registo de Patologias. Fonte: do autor

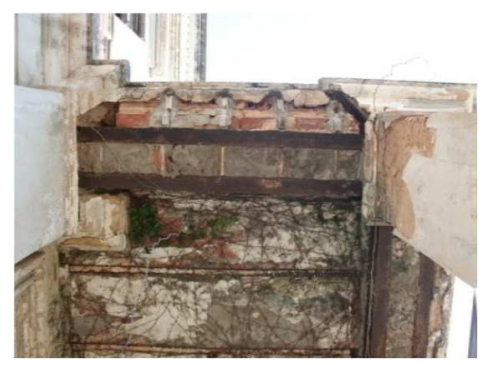

Figura 15: Corrosão de elementos metálicos. Fonte: do autor

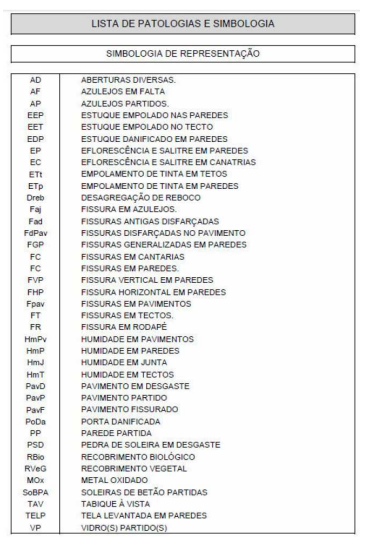

Figura 12: Simbologia de representação. Fonte: do autor

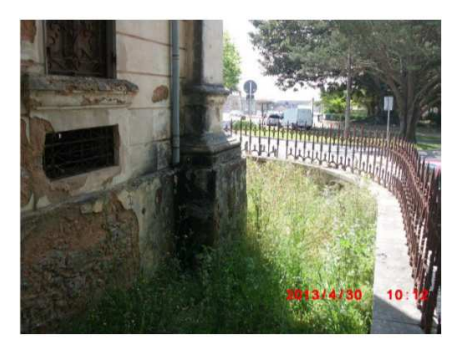

Figura 14: Desagregação de reboco. Fonte: do autor

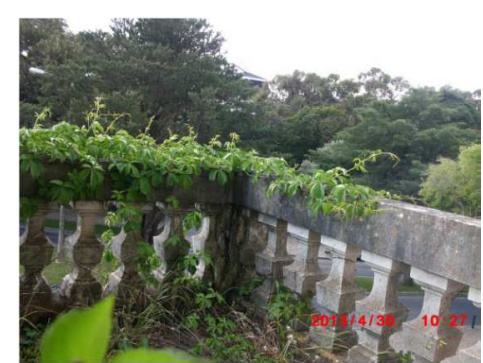

Figura 16: Recobrimento biológico. Fonte: do autor 
O estado de abandono em geral provocou ao longo dos tempos patologias de origens semelhantes em todas as fachadas, com acomodação biológica das fachadas [Figura 17], proporcionando uma aceleração da deterioração dos revestimentos, tendo como resultado a desagregação do reboco.

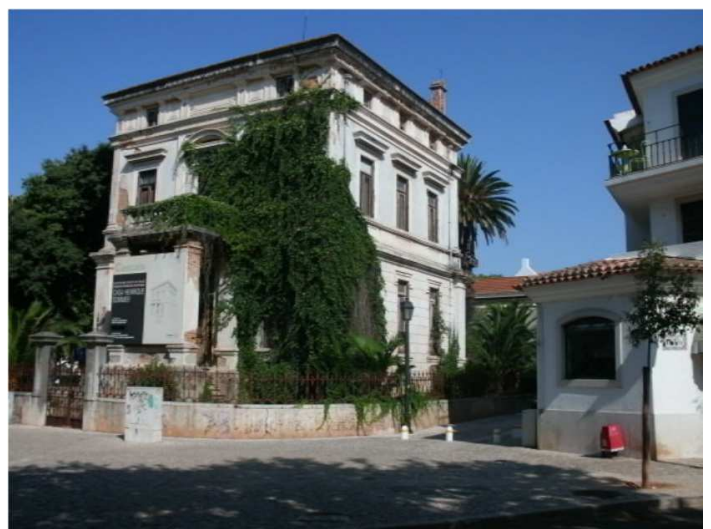

Figura 17: Recobrimento biológico das paredes Sul e Nascente. Fonte: do autor

O pavimento em contato com o solo encontra-se com um grau de humidade elevado em resultado da deficiente ou ausência de uma adequada imperialização, permitindo consequentemente a entrada direta de águas pluviais no espaço interior, causando danos diretamente nos pavimentos e rodapés e ainda, por capilaridade, provocando empolamentos e desagregação de rebocos.

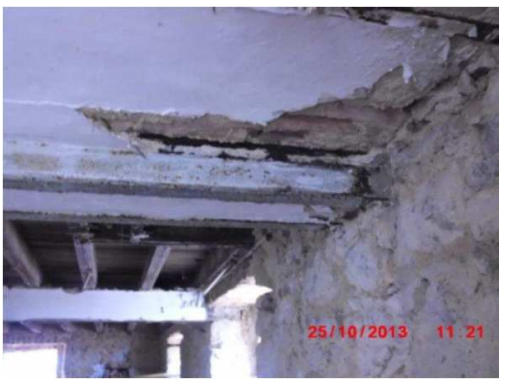

Figura 18: Teto do Piso Térreo. Fonte: do autor

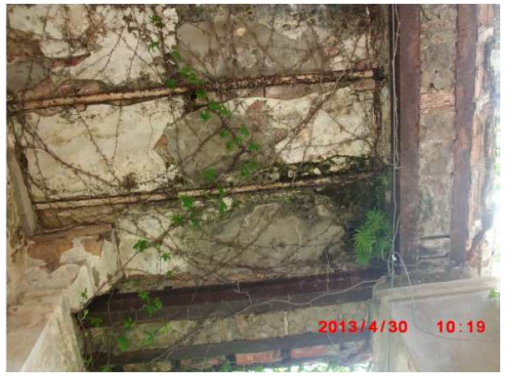

Figura 19: Teto do Pórtico. Fonte: do autor

A estrutura de suporte do pavimento da cozinha revestido em mosaico hidráulico, constituída por perfis metálicos de suporte e abobadilhas argamassadas, afetada pelo ambiente húmido do existente no piso inferior, encontra-se em estado avançado de degradação, sendo notória a oxidação dos seus elementos metálicos [Figura 18].A laje do terraço existente no Piso 2, assente sobre o pórtico de entrada, além de anomalias semelhantes às detetadas na laje da cozinha, aqui pela sua exposição ao ambiente agressivo exterior, são agravadas [Figura 19].

Estas patologias resultam da corrosão por despassivação da estrutura metálica, numa reação induzida por carbonatação, devido estarmos na presença de uma estrutura com uma exposição ambiental ao ar e à humidade e ainda à corrosão provocada por cloretos marinhos provenientes de sais oriundos da água do mar, transportados pelo ar, já que lhe fica próximo.

De acordo com classificação da Norma NP EN 206-1:2007, norma que estabelece aspetos relacionados com o betão, nomeadamente a especificação e desempenho em conformidade com a exposição ambiental, tendo em consideração um dos fatores principais de ataque ao betão que contém armaduras ou com elementos metálicos:

- O ataque sobre as armaduras ou outros metais embebidos (corrosão induzida por carbonatação ou por iões cloreto).

O edifício que foi alvo de estudo, e face à constatação da sua localização de grande proximidade com o mar, poderemos atribuir a Classe XC 3 à corrosão induzida por carbonatação, e ainda a Classe XS1 à corrosão induzida por cloretos marinhos provenientes de sais com origem na água salgada, de acordo com o estabelecido na Tabela 2: Classificação das Ações Ambientais. 
Tabela 2 - Classificação das Ações Ambientais (NP EN 206-1:2007)

\section{CORROSÃO INDUZIDA POR CARBONATAÇÃO}

\begin{tabular}{|c|l|l|}
\hline Classe & Ambiente & Exemplos \\
\hline XC 1 & $\begin{array}{l}\text { Seco ou permanentemente } \\
\text { húmido }\end{array}$ & $\begin{array}{l}\text { Betão no interior de edifícios, com baixa humidade do ar; Betão } \\
\text { permanentemente submerso em água }\end{array}$ \\
\hline XC 2 & Húmido, raramente seco & $\begin{array}{l}\text { Superfícies de betão sujeito a longos períodos de contacto com a } \\
\text { água; Muitas fundações }\end{array}$ \\
\hline XC 3 & Moderadamente húmido & $\begin{array}{l}\text { Betão no interior de edifícios, com moderada ou elevada humidade do } \\
\text { ar; Betão no exterior protegido da chuva. }\end{array}$ \\
\hline XC 4 & Clinicamente húmido e seco & $\begin{array}{l}\text { Superfícies de betão sujeitas ao contacto com a água, fora do âmbito } \\
\text { da classe XC2 }\end{array}$ \\
\hline
\end{tabular}

\section{CORROSÃO INDUZIDA POR CLORETOS DA ÁGUA DO MAR: CLASSE XS}

\begin{tabular}{|l|l|l|}
\hline Classe & Ambiente & Exemplos \\
\hline XS 1 & $\begin{array}{l}\text { Ar transportando sais marinhos } \\
\text { mas sem contacto direto com a } \\
\text { água do mar }\end{array}$ & Estruturas na zona costeira ou na sua proximidade \\
\hline XS 2 & Submersão permanente & Partes de estruturas marítimas \\
\hline XS 3 & $\begin{array}{l}\text { Zonas de marés, de rebentação } \\
\text { ou de salpicos }\end{array}$ & Partes de estruturas marítimas \\
\hline
\end{tabular}

No Piso 2 e Piso 3 - pavimentos e estrutura de suporte nas áreas das instalações sanitárias apresentam-se apodrecidos [Figura 20], anomalia provocada por roturas dos sistemas de águas e/ou de esgotos, salientando-se o facto de o mesmo ser em soalho o que facilitou a derrocada do teto do piso confinante [Figura 21].

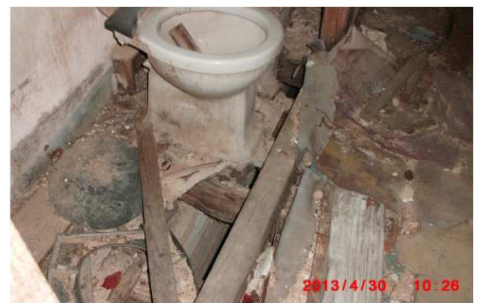

Figura 20: Pavimento das Inst. Sanitárias. Fonte: do autor

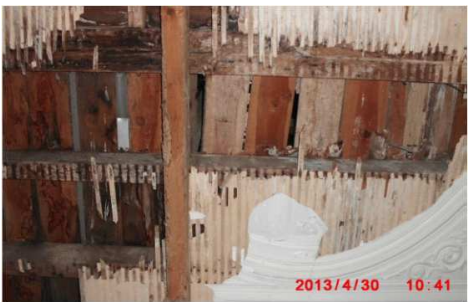

Figura 21: Teto sob as I.S. Fonte: do autor

Devido aos efeitos provocados pelas roturas dos sistemas de abastecimento de aguas e/ou da rede de drenagem das Instalações Sanitárias dos pisos superiores, os tetos na aérea afetada encontram-se em derrocada, apresentando-se com queda da estrutura de suporte ao estuque [Figura 22].

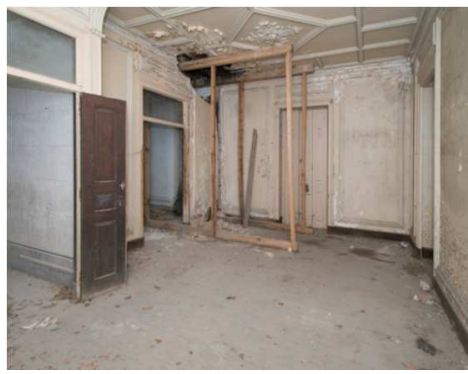

Figura 22: Teto do Salão Nobre. Fonte: do autor 
Devido aos efeitos provocados pelas roturas dos sistemas de abastecimento de aguas e/ou da rede de drenagem das Instalações Sanitárias dos pisos superiores, os tetos na aérea afetada encontram-se em derrocada, apresentando-se com queda da estrutura de suporte ao estuque [Figura 23].

\section{PROPOSTA PARA ESTABILIZAÇÃO ESTRUTURAL}

"utilitas, venustas e firmitas", Vitrúvio (século I aC): Os seus padrões de proporções e os seus princípios conceptuais utilidade, beleza e solidez.

Desde a Antiguidade que, muito embora se restringisse a um território limitado da época Romana, existem registos de normas regulamentares sobre proteção de património: Decreto de cerca do ano 44 d.C., descoberto na cidade histórica de Herculano, Itália - obrigando a quem demolisse um edifício com fins especulativos a pagar às autoridades o dobro do preço da compra. Na vigência do império romano surge um Édito datado de 17 de julho do ano 389 - "É proibido desfigurar os ornamentos exteriores dos edifícios privados com acrescentos modernos e danificar as construções históricas de uma cidade importante por razões de cobiça, por ânsia de lucro”.

O papa Gregório I (590-604) propõe e pratica uma política de reutilização do imenso legado romano abandonado apos a queda do Imperio Romano do Ocidente. As grandes domus patrícias são transformadas em mosteiros, as suas salas de receção em igrejas. Aos seus missionários adverte para a não destruição dos templos e edifícios pagãos, mas antes pelo contrário deverão ser conservados e preparados e devidamente adaptados - colocando os seus altares e as suas relíquias, para o culto cristão (VAZ, 2019).

O Euro código EC 8, parte 3 - "Avaliação e reabilitação de edifícios", estabelece os critérios para avaliação do desempenho sísmico dos edifícios existentes, descrevendo a abordagem quanto às medidas corretivas a tomar. Estabelece ainda critérios para as medidas de reparação e/ou reforço dos elementos estruturais na conceção e dimensionamento final dos novos elementos a introduzir e das suas necessárias ligações ao sistema estrutural original. Os elementos estruturais em madeira, em conjunto com as alvenarias, são de igual importância para a estabilidade do edifício. Pela sua grande vulnerabilidade aos agentes de deterioração e face à necessidade de adaptação da construção às novas utilizações e critérios de segurança atualmente exigíveis, torna-se absolutamente necessário prever uma intervenção adequada, visando o aumento da resistência do elemento deteriorado, quer seja através do seu reforço com recurso à aplicação de novos materiais e/ou através da reconstituição da secção com anomalias, usando o mesmo material - com ou sem elementos de ligação (CÓIAS, 2007).

Com recurso a um modelo básico que simboliza a génese da estrutura do primeiro abrigo construído pelo Homem, procurou-se conceber um Arquétipo, que de uma forma simples e esquemática resuma a estrutura do estudo.

Introdução de próteses - representadas a preto nas fotografias, para as seções danificadas do elemento: Reparação do tipo A: no seu apoio inferior [Figura 23]; Reparação do tipo B: no seu apoio superior [Figura 24];Reparação do tipo C: em qualquer parte em que se verifique a existência de anomalia [Figura 25]; Reparação do tipo D: substituição integral do elemento [Figura 26].

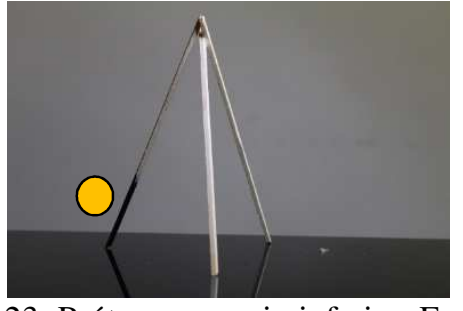

Figura 23: Prótese no apoio inferior. Fonte: do autor

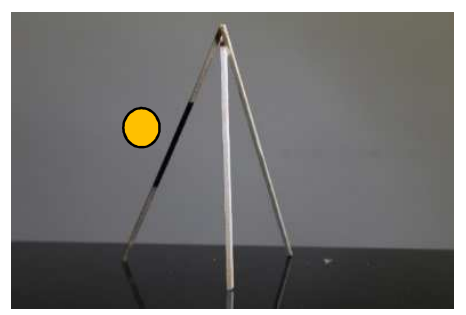

Figura 25: Prótese de localização variável. Fonte: do autor

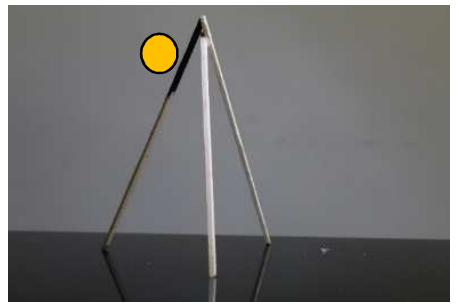

Figura 24: Prótese no apoio superior. Fonte: do autor

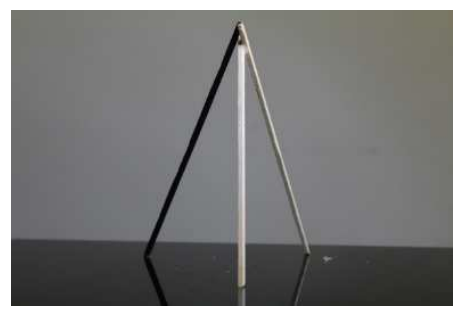

Figura 26: Novo elemento de substituição. Fonte: do autor 


\section{CONSIDERAÇÕES FINAIS}

O Património Arquitetónico não poderá ser avaliado unicamente sob a perspetiva da sua conceção original, mas também e sobretudo pelo resultado final de adaptações sucessivas durante e no decorrer da sua utilização, como sejam alterações e/ou substituições parciais ou totais dos sistemas tectónicos primordiais. Uma correta perceção do edifício de modo a se adquirir a fundo o conhecimento de todos os procedimentos da arte, numa análise minuciosa de cada um e conjuntamente com todos os vários períodos ao longo da sua existência para que, em caso de necessidade, restabelecer qualquer parte do edifício numa consciente adição à construção existente, assumindo, contudo, a intervenção de uma forma identificada, onde as tentativas de cópias dos elementos serão interditas, preservando os valores da memória histórica coletiva.

O trabalho de campo realizado proporcionou, ao longo da abordagem e recolha de informação sobre o edifício alvo do estudo, com recurso a inspeções visuais e a sondagens não destrutivas, todo um conhecimento e a compreensão do conceito estrutural da preexistência, dos materiais e sistemas construtivos que a compõem, prestando um significativo contributo para o desenho de uma intervenção consciente, sustentada no domínio do saber resultante de uma cuidada avaliação das suas patologias e das suas causas.

Embora as técnicas defendidas neste estudo sejam classificadas como pouco intrusivas, considera-se que são suficientes para atingir os objetivos pretendidos, sem provocar alterações no funcionamento do sistema estrutural original e dos diversos constituintes elementos estruturais preexistentes, numa perfeita comunhão entre o mundo da arte passado e atual, o mundo contemporâneo e a modernidade técnica hoje disponibilizada.

O aumento da resistência das alvenarias pode ser atingido com relativa facilidade através de reforço por confinamento, por adição de um novo material (compósitos, redes, chapas ou perfis metálicos). A estrutura de madeira será preservada pela reconstituição/reposicionamento do elemento com o mesmo material e/ou material diferente do original, próteses ou ainda pela inserção de novos elementos estruturais, cuja resistência possa ser mobilizada de forma a transferir as cargas entre a estrutura a reforçar e esse novo elemento.

O grande desafio será garantir a melhoria do comportamento global do edifício, em resultado da reparação/substituição cuidada das alvenarias e das madeiras estruturais, restabelecendo as suas funções estruturais agora reforçadas pela intervenção. A pretensão do artigo, muito embora se trate de um trabalho académico, considerando o seu nível de investigação e avaliação in loco, é a de apresentar uma metodologia de atuação inteligível, a partir do qual se poderá desenvolver e aplicar na Reabilitação do Património Arquitetónico a intervenção que se defende, reunindo num só discurso os conceitos de autenticidade, pátina e estratificação temporal - reconhecimento e valorização das várias intervenções que afetam os edifícios, em que as práticas não se contrapõem, fazendo com que ambas sejam inseridas numa abordagem de igual importância.

\section{REFERÊNCIAS}

COIAS, V. Reabilitação Estrutural de Edifícios Antigos. 2 ed. Lisboa: Argumentum/Gecorpa, 2007.

LOPES, F. \& CORREIA, M. Património Cultural - Critérios e Normas Internacionais de Proteção. Lisboa: Caleidoscópio, 2014.

MASCARENHAS, J. Sistemas de construção - Técnicas para a reabilitação de edifícios. Lisboa: Livros Horizonte, 2019.

PAIVA, C. \& SOUZA, A. Manual para quem vive em casas tombadas. Ouro Preto: Legraphar, 2018.

SOUSA, L. et al, Monumentos 31. Lisboa: I.H.R.U, 2001.

VAZ, P. Edificar no Património: pessoas e paradigmas na conservação \& restauro. Lisboa: Edições 70, 2019. 